\title{
The speed of reinfusion affects the vascular system during ozone major autohemotherapy
}

\author{
Daniele Rimini, ${ }^{1}$ Filippo Molinari, ${ }^{1}$ William Liboni, ${ }^{2}$ Vincenzo Simonetti, ${ }^{3,4}$ Marianno Franzini ${ }^{3}$ \\ ${ }^{1}$ Department of Electronics and Telecommunications, Politecnico di Torino, Turin; ${ }^{2}$ Un passo insieme \\ ONLUS Foundation, Valdellatorre (TO); ${ }^{3}$ Scientific Society of Oxygen-Ozone Therapy, Gorle (BG); \\ ${ }^{4}$ Kaos non-profit Association, Caselle Torinese (TO), Italy
}

\begin{abstract}
Ozone major autohemotherapy (0-MAHT) is a way of ozonetherapy administration consisting of drawing patient's venous blood, mixing with oxygen/ozone, and reinfusing it into the vein. Some ozone therapists reported side effects during the 0-MAHT, but the origin has not been described yet. We investigated the effect of blood drawing velocity during 0-MAHT to see its effects on the vascular system and symptomatology. We administered 0-MAHT to 11 subjects, and we interleaved fast and slow reinfusions. We monitored cerebral macrocirculation with transcranial Doppler (TCD) and tissue microcirculation with near-infrared spectroscopy (NIRS). Annoying symptoms appeared just during the fast reinfusion periods. NIRS and TCD parameters revealed vasoconstriction during fast reinfusion and improved metabolism during slow reinfusion. Overall, our investigation well discriminated fast from slow reinfusion velocity.
\end{abstract}

\section{Introduction}

The main benefits of ozone therapy on humans are: the antibiotic effect and static effect on viruses, ${ }^{1-4}$ activation of the mitochondrial antioxidant system, ${ }^{5-7}$ increased adenosine triphosphate (ATP) production, hemorheological effect with greater activity of the oxygen-car-

Correspondence: Vincenzo Simonetti, Scientific Society of Oxygen-Ozone Therapy, via Roma 69 , Gorle (BG), Italy.

Tel/Fax: +39.035.300903.

E-mail: simonetti.vinc@gmail.com

Key words: Ozone autohemotherapy; Reinfusion velocity; Near-infrared spectroscopy; Transcranial Doppler.

Received for publication: 16 November 2016.

Accepted for publication: 14 December 2016.

(C) Copyright D. Rimini et al., 2016

Licensee PAGEPress, Italy

Ozone Therapy 2016; 1:6477

doi:10.4081/ozone.2016.6477

This article is distributed under the terms of the Creative Commons Attribution Noncommercial License (by-nc 4.0) which permits any noncommercial use, distribution, and reproduction in any medium, provided the original author(s) and source are credited. bon dioxide exchange in red blood cells, ${ }^{8}$ and anti-inflammatory action. ${ }^{9}$ In addition, there is reactivation of the cerebral microcirculation and metabolism, ${ }^{7}$ an anti-ischemic protective effect, ${ }^{10-12}$ antithrombotic effect, ${ }^{13}$ and anti-tumor action.

For several decades these properties have prompted its use in orthopedic diseases such as osteoarthritis, arthritis, and herniated discs, ${ }^{14-16}$ contributing significantly to the reduction in surgical treatment and improving patients' quality of life; moreover, arterial and venous vascular diseases, and metabolic, autoimmune, infectious and neoplastic diseases also benefit from it. ${ }^{17,18}$ Ozone induces the repair of tissue damage through the release of several growth factors and by activating the body's own stem cells. ${ }^{19,20}$

The occurrence of side effects during ozone therapy is still controversial: while some studies report the total absence of adverse effects, ${ }^{6,21}$ other authors have reported side effects, especially for local, intradiscal and paravertebral injections: ${ }^{22,23}$ there have been reports of burning sensations with subcutaneous injections at high concentrations and pain due to distension of the muscle fascia with paravertebral injections for herniated discs. This sensation can be reduced by injecting more slowly, at lower ozone concentrations and with reduced volumes of gaseous mixture. However, the studies published have not reported that ozone is directly responsible.

Another mode of administration for ozone therapy is ozone major autohemotherapy (0-MAHT). This consists in drawing venous blood from the patient, usually from 100 to $240 \mathrm{~g}$, and after the blood is mixed with an oxygen/ozone $\left(\mathrm{O}_{2}-\mathrm{O}_{3}\right)$ mixture, it is reinfused through the same vein. In the guidelines on the practice of 0-MAHT, it is often suggested that low ozone concentrations and stoichiometric amounts be used with respect to the blood to be treated for an overall reduction in side effects. ${ }^{24,25}$ However, some ozone therapy practitioners have observed the sporadic appearance of perioral paresthesia, feelings of warmth and/or tachycardia, sensations of coolness in the chest area, and fainting during O-MAHT. These side effects may arise from reinfusing the blood- $\mathrm{O}_{2}-\mathrm{O}_{3}$ mixture too quickly. In fact, as has already been pointed out in an earlier study ${ }^{7}$ fast reinfusion may cause an increase in peripheral resistance, probably due to the effect of the volume that induces a response from the autonomic nervous system underlying the reported side effects.

Given the fact that no studies have been found in the literature that make clear reference to adverse effects resulting from the different speeds of reinfusion of the blood- $\mathrm{O}_{2}-\mathrm{O}_{3}$ mixture during 0 -MAHT, the aim of this article is to verify whether the speed of reinfusion during 0 MAHT could be correlated with such events. We therefore concomitantly monitored both the blood flow through the middle cerebral artery (MCA), using the transcranial Doppler method (TCD), and the microcirculation, using near-infrared spectroscopy (NIRS). The first method permits the measurement of the speed of the blood flow and the peripheral resistance. ${ }^{26}$ NIRS permits the evaluation of tissue oxygenation, which is closely related to a greater or lesser opening of the microcirculation. ${ }^{27}$ 
Both are suitable for continuous monitoring of cerebral hemodynamics as they are relatively inexpensive and non-invasive methods.

\section{Materials and Methods}

The study involved an analysis of the effect of the speed of reinfusion during 0-MAHT. For this reason, changes in the micro- and macro-circulation were measured in a group of 11 subjects using NIRS and TCD signals respectively. These signals were divided into observation windows of interest. Within each window, quantitative parameters were measured in the time domain, frequency domain and indices of interest.

\section{Subjects}

A sample of 6 control subjects with no previous history of brain disorders was analyzed. Five subjects with a history of inflammatory neurological or neurodegenerative disease were also analyzed: in particular, the sample included two patients with relapsing-remitting multiple sclerosis (MS), two subjects suffering from disorders of movement Parkinsonism, and one with arterial hypertension. In total, 11 subjects were analyzed. A heterogeneous sample was selected to evaluate whether or not the adverse effects reported by some authors during 0 MAHT were due to a specific pathology. All subjects signed informed consent after being informed about the procedures, timing, purpose and potential side effects of the examination.

\section{Autohemotherapy}

Each subject was placed on an examination couch in the supine position in a quiet, comfortable room. In addition, subjects was asked to keep their eyes closed and breath normally. Of venous blood, $180 \mathrm{~g}$ was drawn from a vein in the subject's arm. A mixture of $180 \mathrm{~mL} \mathrm{O}_{2}-\mathrm{O}_{3}$ with an $\mathrm{O}_{3}$ concentration of $40 \mu \mathrm{g} / \mathrm{mL}$ was added to the blood, and lastly, after suitable slow mixing, the blood $-\mathrm{O}_{2}-\mathrm{O}_{3}$ mixture was reinfused by gravity into the same vein as was used to draw the patient's blood. A Medical 95 CPS ozone-dispensing machine from Multiossigen Srl [Gorle (BG), Italy] and a SANO3 kit for autohemotherapy from Haemopharm Healthcare Srl [Sondalo (SO), Italy] were used. The blood was reinfused at two different speeds: fast reinfusion and slow reinfusion. The speed of reinfusion was varied by changing the height of the bag containing the blood- $\mathrm{O}_{2}-\mathrm{O}_{3}$ mixture: for fast reinfusion, the height was set at about $60 \mathrm{~cm}$ from the patient's heart level, while for slow reinfusion the height was lowered to about $20-30 \mathrm{~cm}$ from the heart level. The speed of the mixture flowing out from the bag was over $80 \mathrm{drops} / \mathrm{min}$ during fast reinfusion, while during slow reinfusion it was less than 50 drops/min. It was not necessary to continuously measure the speed of reinfusion: in fact, the point of interest was not the exact speed but to highlight any different sensations felt by the same patient in relation to the different speeds of reinfusion. This difference, due to the gravitational effect, was ensured by the difference in the height of the position of the bag. In addition, fast reinfusion was alternated with slow reinfusion in order to reduce the amount of time in which the subjects felt any discomfort. The change in speed occurred after having reinfused approximately $50 \mathrm{~g}$ of the mixture.

In summary, the following windows of observation were defined: baseline; blood collection; first fast reinfusion of the mixture (FAST1); slow reinfusion of the mixture (SLOW); second fast reinfusion of the mixture (FAST2).

\section{Test measurements}

The NIRS recordings were made by constantly using a two-channel commercial device (NIR0200NX, Hamamatsu Photonics, Japan) throughout the examination time. The NIRS probes (nominal peak wavelength of 735,810 , and $850 \mathrm{~nm}$ ) were positioned at the level of the frontal lobe of the dominant hemisphere and the right tibialis anterior muscle. The brain probe was placed on the subject's forehead $2 \mathrm{~cm}$ from the midline and $1 \mathrm{cmabove}$ the supraorbital ridge. Information was thus obtained on the microcirculation in the cerebral and peripheral tissue. The relative concentrations of oxygenated $(02 \mathrm{Hb})$ and deoxygenated (HHb) hemoglobin were recorded. The total hemoglobin value (totHb) was also determined as the sum of $02 \mathrm{Hb}$ and $\mathrm{HHb}$. The signals were sampled at a frequency of $2 \mathrm{~Hz}$ and analyzed in the time domain and frequency domain In the time domain, the relative average concentration values of $\mathrm{O2} \mathrm{Hb}$ and $\mathrm{HHb}$ were measured in each window of observation. In the frequency domain, the signals were analyzed using time-frequency analysis since the NIRS signal is not stationary. A Cohen's class ChoiWilliams (CW) distribution was used with a Gaussian kernel with $\sigma=0.5 .^{28}$ The relative power of the $02 \mathrm{Hb}$ and $\mathrm{HHb}$ signals was measured from the CW in three bands of interest: very-low frequency (VLF) in the 20-60 $\mathrm{MHz}$ band, low frequency (LF, 60-140 MHz) and high frequency (HF, 140-250 mHz). The VLF band is linked to long-term motor vasoreactivity. The LF band is related to the activity of the sympathetic and parasympathetic system, and therefore to cerebral autoregulation. It is generally a stronger indicator of sympathetic system activity. ${ }^{29,30}$ The HF band is linked to the activity of the vagal nerve. Finally, the LF/HF ratio is indicative of the sympatho-vagal balance and reflects sympathetic modulation. ${ }^{31,32}$ Finally, the total power $\left(\mathrm{P}_{\text {Тот }}\right)$ was measured for cerebral $\left(02 \mathrm{Hb}_{\mathrm{c}}, \mathrm{HHb}_{\mathrm{c}}\right)$ and muscle $\left(02 \mathrm{Hb}_{\mathrm{m}}, \mathrm{HHb}_{\mathrm{m}}\right)$ NIRS parameters. The percentage of relative power for the VLF, LF and HF bands was calculated as $\mathrm{P}_{\mathrm{VLF}} / \mathrm{P}_{\mathrm{TOT}}, \mathrm{P}_{\mathrm{LF}} / \mathrm{P}_{\mathrm{TOT}}$, and $\mathrm{P}_{\mathrm{HF}} / \mathrm{P}_{\mathrm{TOT}}$. These parameters were calculated for $02 \mathrm{Hb}$ and $\mathrm{HHb}$ in all the windows of observation.

The TCD signal was acquired at the same time as the NIRS signal. A commercial device (Delica EMS-9UA; Shenzhen Delicate Electronics Co., Tian-an, China) with a $2 \mathrm{MHz}$ probe was used. The probe was positioned to achieve a flow signal from the right middle cerebral artery over the temporal window at the level of the M1 segment. Within each window, the mean values of the following TCD parameters were measured: peak systolic speed (SS); diastolic downstream speed (DD); gosling pulsatility index (PI); index of resistance (IR); heart rate (HR).

Overall, for each subject, 23 parameters were measured in each window of observation: 5 TCD parameters, 9 NIRS cerebral parameters and 9 NIRS muscle parameters.

Finally, the systemic oxygen saturation and arterial blood pressure (ABP) were monitored throughout the examination at the beginning of each temporal window. The ABP values were used for the calculation of the mean arterial pressure (MAP).

\section{Statistical analysis}

The duration of the reinfusion windows were compared using oneway analysis of variance (ANOVA). The MAP values during the baseline interval and during the reinfusions were compared using one-way ANOVA analysis. Subsequently, the FAST1 and FAST2 windows were averaged thus obtaining a single FAST observation window. Multivariate analysis of variance (MANOVA) was performed with all 23 TCD and NIRS parameters.

\section{Results}

In Table 1 the demographic data of the study sample is shown. It may be noted that the average duration of the FAST1, SLOW, and FAST2 reinfusions did not differ between the control subjects and those affected by disease (one-way ANOVA, $P>0.1$ ). The MAP values in the different observation windows were compared using one-way ANOVA and did not undergo any significant changes during the examination.

All subjects reported at least one of the following side effects during 
fast reinfusions: tingling in the mouth and legs, a metallic taste in the mouth, pulsing temples, a sensation of warmth in the cheeks, a feeling of cold and tightness in the chest. These symptoms occurred during fast reinfusion and immediately disappeared after a reduction in the speed of reinfusion; they reappeared if the speed of reinfusion was increased again.

The percentage change in the concentration of $02 \mathrm{Hb}, \mathrm{HHb}$ and totHb was calculated. The average concentration of the baseline window was taken as a reference. The relative changes are reported in Figure 1 both at the cerebral level (A) and the muscular level (B). In Table 2 the average values of the peak systolic speed SS and DD diastolic downstream speed are reported, as are the indices PI, IR and HR in the 5 windows of observation. It is stressed that the SS increases slightly during fast reinfusion, as do the parameters PI and IR, when compared to slow infusion. In general, one can observe a different organ reaction to the $\mathrm{O}_{2}-\mathrm{O}_{3}$ mixture. In the brain, it can be observed that the concentration of totHb decreases starting from the withdrawal window. Compared with baseline, the blood collection manoeuvers cause a decrease in $02 \mathrm{Hb}$, as in a state of alarm or reactions to pain. During FAST1 reinfusion, and especially during FAST2 reinfusion, we see a reduction in the $02 \mathrm{Hb}$ concentration together with constant $\mathrm{HHb}$. The TCD findings document an increase in the indices of peripheral vascular resistance PI and IR in the territory of the MCA. These conditions point to peripheral vasoconstriction and reduction of the tissue bed of the microcirculation. During slow reinfusion, an increase in the vascular bed of the microcirculation is observed, which is line with the slight increase in the DD and reduction in the IR. At the muscular level, during fast reinfusion vasoconstriction can be observed which manifests as an increase in the concentration of $\mathrm{HHb}$ and a decrease in $02 \mathrm{Hb}$. In the subsequent windows, there is a tendency to increase $02 \mathrm{Hb}$ and decrease $\mathrm{HHb}$. Slow reinfusion favors the use of oxygen with greater representation, particularly in the muscle, of $\mathrm{HHb}$ and constant totHb. The changes in the microcirculation appear on the instrumentation a few seconds before the subject points out the symptoms listed above.

The LF/HF ratio was subsequently calculated in the reinfusion windows, this being indicative of sympathetic and parasympathetic regulation. The average values for all the subjects are shown in Figure 2. It can be observed that the ratio of the powers is lower during slow reinfusion than fast reinfusion.
Lastly, in order to evaluate the different behavior of the modes of reinfusion the curves of the FAST1 and FAST2 windows were averaged into one FAST window for which the average value was calculated.

MANOVA was performed to take into account all the parameters of the macro- and micro-circulation. MANOVA analysis of the FAST and SLOW modes confirms the different effect in the circulation (Wilks' lambda $=0.006)$. A canonical variable allows the fast reinfusion method to be distinguished from the slow mode (Figure 3).

\section{Discussion}

This study was aimed at evaluating the correlation between the occurrence of side effects observed clinically during 0-MAHT and the speed of the reinfusion of the blood $\mathrm{O}_{2}-\mathrm{O}_{3}$ mixture. For this purpose, a group of subjects received 0-MAHT with different reinfusion speed windows. The results obtained showed a modulation in frequency, which is reflected in the subjective symptoms reported.

The positive effects of 0-MAHT have already been documented in one of our earlier studies: ${ }^{7}$ monitoring the tissue microcirculation using NIRS, an increase was observed in brain oxygenation after about 1.5 hours' infusion of ozonated blood. In addition, people with MS have shown an increase in the activity and concentration of cytochrome $c$ oxidase for up to 40 minutes after the end of treatment. These results have shown that a blood- $\mathrm{O}_{2}-\mathrm{O}_{3}$ mixture causes variations in the microcirculation and metabolic changes which are stable over time. These are obtained thanks to the steady-state homogeneous diffusion of the mixture, favored by an infusion rate that helps to achieve this.

However, there was no documentation on the effects of the mode of reinfusion on subjective symptoms. Many of the effects described as adverse in the literature are essentially present during the phase of fast reinfusion and actually seem to be due to iatrogenic action related to incorrect management of the reinfusion times, in particular the speed of reinfusion, rather than related to the toxicity of the molecule.

Regarding the time needed for reinfusion, some variations have been observed compared to the baseline condition, which, besides being present in the microcirculation, also reflect on the macrocirculation.

Table 1. Demographic data (mean \pm standard deviation) of the study sample and duration of the observation windows.

\begin{tabular}{|c|c|c|c|c|c|c|c|c|}
\hline \multirow[t]{2}{*}{ Group } & \multirow[t]{2}{*}{$\mathbf{N}$} & \multirow[t]{2}{*}{ Age (years) } & \multirow[t]{2}{*}{ BMI } & \multicolumn{5}{|c|}{ Duration (s) } \\
\hline & & & & Baseline & Withdrawal & FAST1 & SLOW & FAST2 \\
\hline Healthy & 6 & $58.7 \pm 17.3$ & $25.3 \pm 3.3$ & $223.2 \pm 34.4$ & $135.7 \pm 83$ & $186.1 \pm 41.7$ & $343.8 \pm 139.2$ & $124.7 \pm 49.8$ \\
\hline Pathology & 5 & $53.5 \pm 15.8$ & $22.7 \pm 2.1$ & $271.9 \pm 33.2$ & $120.4 \pm 59.1$ & $152.6 \pm 88.8$ & $286.1 \pm 171.6$ & $145.6 \pm 70.4$ \\
\hline Total & 11 & $56.8 \pm 16.1$ & $24.3 \pm 3.1$ & $240.9 \pm 40.5$ & $130.1 \pm 72.4$ & $174 \pm 60.8$ & $322.8 \pm 146$ & $132.3 \pm 55.6$ \\
\hline
\end{tabular}

BMI, body mass index; FAST1, fast reinfusion period 1; SLOW, slow reinfusion period; FAST2, fast reinfusion period 2.

Table 2. Transcranial Doppler parameters (mean \pm standard deviation) in the five windows of observation.

\begin{tabular}{llllll} 
& SS $(\mathrm{cm} / \mathrm{s})$ & DD $(\mathrm{cm} / \mathrm{s})$ & PI & IR \\
Baseline & $64.222 \pm 12.99$ & $26.795 \pm 4.75$ & $0.876 \pm 0.19$ & $0.570 \pm 0.085$ & $50.365 \pm 8.30$ \\
Withdrawal & $63.985 \pm 17.18$ & $28.315 \pm 5.79$ & $0.819 \pm 0.15$ & $0.549 \pm 0.062$ & $55.634 \pm 8.08$ \\
\hline FAST1 & $66.016 \pm 15.52$ & $29.099 \pm 6.36$ & $0.827 \pm 0.16$ & $0.552 \pm 0.07$ & $52.257 \pm 7.06$ \\
SLOW & $65.010 \pm 16.94$ & $29.187 \pm 8.42$ & $0.819 \pm 0.16$ & $0.550 \pm 0.06$ & $54.389 \pm 9.04$ \\
\hline FAST2 & $66.854 \pm 16.60$ & $28.631 \pm 6.84$ & $0.854 \pm 0.16$ & $0.566 \pm 0.07$ & $53.851 \pm 6.36$
\end{tabular}

SS, systolic speed; DD, diastolic downstream speed; PI, pulsatility index; IR, index of resistance; HR, heart rate; FAST1, fast reinfusion period 1; SLOW, slow reinfusion period; FAST2, fast reinfusion period 2. An increase in systolic speed, downstream speed and heart rate and a decrease in pulsatility index and index of resistance can be observed during the reinfusion with respect to the baseline window. 
Autoregulation in the brain by variations in volume in the microcirculation, in particular of the venous outflow, is regulated mainly by the autonomic nervous system and is closely related to the compliance of the intracranial pressure (ICP). The changes in these parameters during the period of drug treatment (FAST1 to FAST2 windows) could be the cause of the subjective symptoms: indeed, the variations in volume caused by reinfusion affect the autonomic nervous system, as demon- strated by changes in the LF/HF ratio. Given the constant MPA, this effect can only be related to the CPP (Cerebral Partial Pressure) changes. This hypothesis is supported by the changes in speed in the $\mathrm{SS}$ and in the IP and IR indices. The changes in volume reflect on the ICP and, therefore, on the resistances and the compliance of the flow, as a result of an autoregulation mechanism of the autonomic nervous system. Overall, the spectrographic NIRS findings and TCD flow rates

(A)

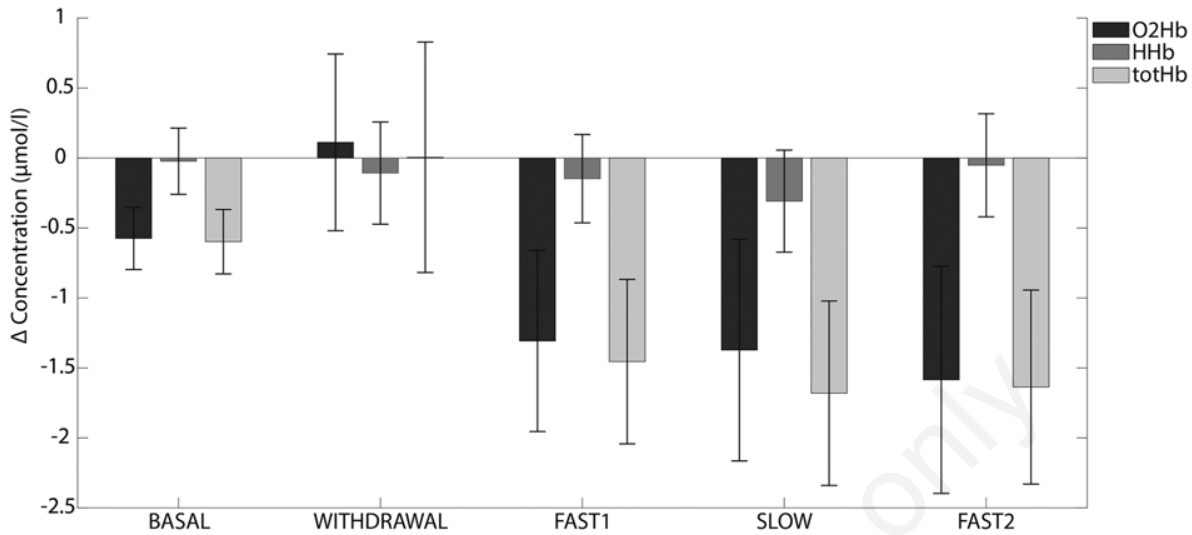

(B)

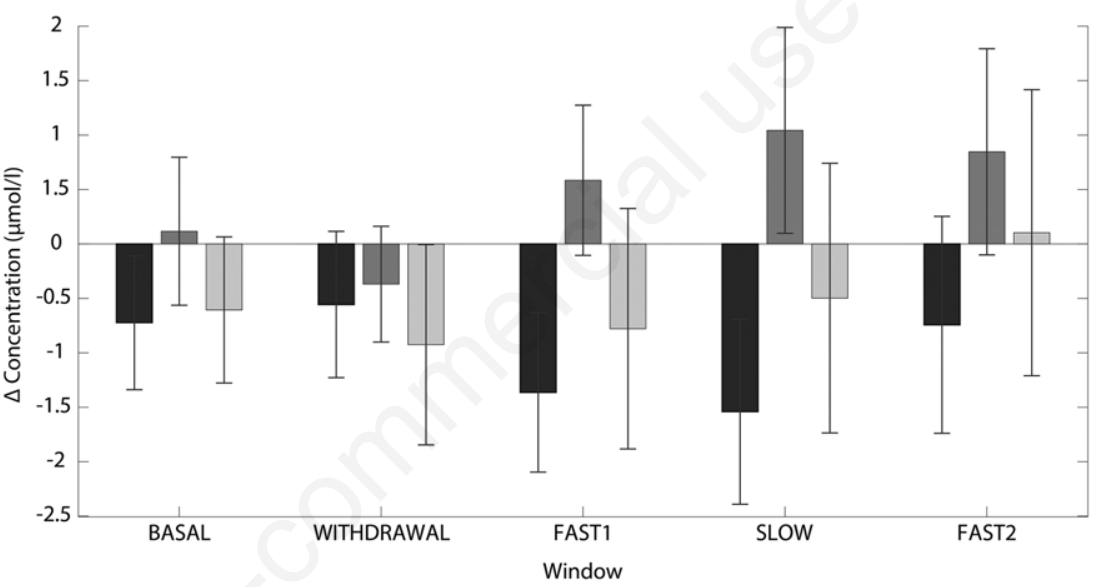

Figure 1. The mean value and standard error of the average concentration of oxygenated, deoxygenated, and total hemoglobin $(\mathrm{O} 2 \mathrm{Hb}$ $\mathrm{HHb}$, and totHb, respectively) with respect to the baseline window in the baseline, sampling, fast reinfusion (FAST1 and FAST2) and slow reinfusion (SLOW) windows. In the brain (A), there was an average decrease in $\mathrm{O} 2 \mathrm{Hb}$, accompanied by an almost constant concentration of $\mathrm{HHb}$. In the muscle $(\mathrm{B})$, a progressive increase in the $\mathrm{HHb}$ concentration and a decrease in $\mathrm{O} 2 \mathrm{Hb}$ concentration were observed and were greater in the slow reinfusion window.

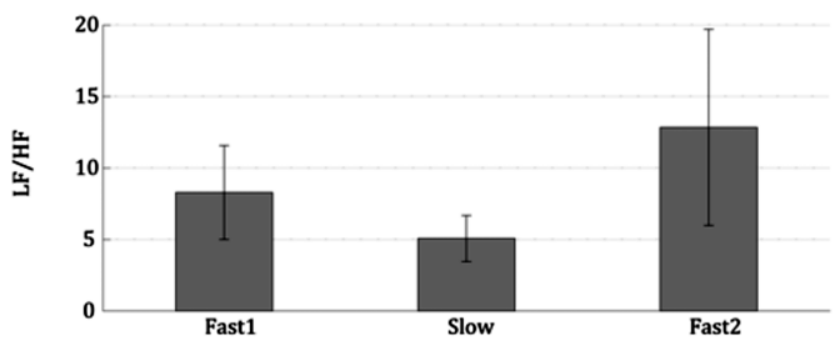

Figure 2. Average percentage value of the low/high frequency (LF/HF) ratio in the fast (FAST1 and FAST2) and slow (SLOW) brain windows. The ratio is lower in the slow reinfusion window than in the fast reinfusion windows.

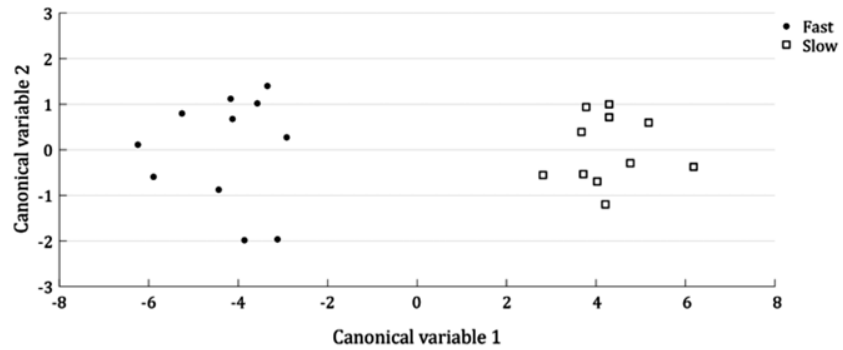

Figure 3. Result of the MANOVA for the two modes of reinfusion FAST (circles) and SLOW (squares). The two modes are well separated in the plane of the two canonical variables. 
indicate changes in muscle tone, in the precapillary sphincters and in the tone in sympathetic venular outflow that influence CPP and thus ICP. This activity of the autonomic nervous system allows, in the analysis of the overall system, two areas to be identified which are defined according to the mode of reinfusion. In the muscle, as in the brain, we have the spectral modifications that confirm the variations in circulation in relation to changes in the sympathetic-parasympathetic tone.

To summarize, we have: i) from a clinical point of view, modulating autonomic-sympathetic symptoms; ii) in terms of clinical tests, the TCD-NIRS measurements which indicate an autoregulatory response to an increase in systemic $\mathrm{O}_{2}$; and iii) the pharmacological action of ozone, thus a stimulus with a strong redox action, because besides changes in the circulation, variations in the cellular energy metabolism probably take place as well.

\section{Conclusions}

The study presented was designed to investigate the effect of the speed of reinfusion during 0-MAHT. A group of subjects received two speeds of reinfusion and the micro- and macro-circulations at the peripheral and cerebral levels were measured. The instrumental analysis showed different behaviors in the two conditions due to different actions from the autoregulation mechanisms and variation in the peripheral resistance. Future studies will involve the enrolment of a larger number of subjects and the comparison of symptoms and vascular parameters during reinfusion in alternative conditions to ozone. In addition, a working hypothesis emerging from the analysis of the data collected could be that, from a functional point of view, there is a better activity of the energy metabolism in the brain tissues in clinically healthy patients.

\section{References}

1. Hems RS, Gulabivala K, Ng YL, et al. An in vitro evaluation of the ability of ozone to kill a strain of Enterococcus faecalis. Int Endod J 2005;38:22-9.

2. Polydorou 0, Pelz K, Hahn P. Antibacterial effect of an ozone device and its comparison with two dentin-bonding systems. Eur J Oral Sci 2006;114:349-53.

3. Huth KC, Quirling M, Lenzke S, et al. Effectiveness of ozone against periodontal pathogenic microorganisms. Eur J Oral Sci 2011;119:204-10.

4. Marx J. Antibodies kill by producing ozone. Science 2002;298:1319.

5. Merin 0, Attias E, Elstein D, et al. Ozone administration reduces reperfusion injury in an isolated rat heart model. J Card Surg 2006;22:339-42.

6. Martínez-Sánchez G, Delgado-Roche L, Díaz-Batista A, et al. Effects of ozone therapy on haemostatic and oxidative stress index in coronary artery disease. Eur J Pharmacol 2012;691:156-62.

7. Molinari F, Simonetti V, Franzini M, et al. Ozone autohemotherapy induces long-term cerebral metabolic changes in multiple sclerosis patients. Int J Immunopathol Pharmacol 2014;27:379-89.

8. Inal M, Dokumacioglu A, Ozcelik E, Ucar 0. The effects of ozone therapy and coenzyme Q10 combination on oxidative stress markers in healthy subjects. Ir J Med Sci 2011;180:703-7.

9. Souza YM De, Fontes B, Martins J0, et al. Evaluation of the effects of ozone therapy in the treatment of intra-abdominal infection in rats. Clinics 2010;65:195-202.

10. Elvis AM, Ekta JS. Ozone therapy: a clinical review. J Nat Sci Biol Med 2011;2:66-70.

11. D’Amico M. [Trattamento ozonoterapico nel pre post-infarto mio- cardico sperimentale indotto nei ratti. Congresso Ozonoterapia]. [Proceedings in Italian]. Bergamo: Scientific Society of OxygenOzone Therapy; 2007.

12. Ferrero ME. Enhancement of endothelial cell function by ozoneoxidative treatment. Bergamo: Scientific Society of Oxygen-Ozone Therapy; 2007.

13. Maslennikov 0, Sharov I, Potekhina I, et al. Effect of ozone therapy on hemostatic changes in patients with vascular atherosclerosis. Klin Med 1997;75:35-7.

14. Muto M, Andreula C, Leonardi M. Treatment of herniated lumbar disc by intradiscal and intraforaminal oxygene-ozone (02-03) Injection. J Neuroradiol 2004;31:183-9.

15. Paoloni M, Di Sante L, Cacchio A, et al. Intramuscular oxygenozone therapy in the treatment of acute back pain with lumbar disc herniation. Spine 2009;34:1337-44.

16. Buric J, Rigobello L, Hooper D. Five and ten year follow-up on intradiscal ozone injection for disc herniation. Int J spine Surg 2014;8:17.

17. Clavo B, Pérez JL, López L, et al. Ozone therapy for tumor oxygenation: a pilot study. Ev Complem Altern Med 2004;1:93-8.

18. Bocci V, Larini A, Micheli V. Restoration of normoxia by ozone therapy may control neoplastic growth: a review and a working hypothesis. J Altern Complement Med 2005;11:257-65.

19. Zänker KS, Kroczek R. In vitro synergistic activity of 5-fluorouracil with low-dose ozone against a chemoresistant tumor cell line and fresh human tumor cells. Chemotherapy 1990;36:147-54.

20. Alam Khan F. Ozone induced cell death in hela cell culture mediated through stimulation of TNF- alpha. MOJ Immunol 2015;2:2-7.

21. Tylicki L, Biedunkiewicz B, Rachon D, et al. No effects of ozonated autohemotherapy on inflammation response in hemodialyzed patients. Mediators Inflamm 2004;13:377-80.

22. Vanni D, Galzio R, Kazakova A, et al. Intraforaminal ozone therapy and particular side effects: preliminary results and early warning. Acta Neurochir 2016;158:491-6.

23. Üreyen Ç, Baş C, Arslan Ş. Myocardial infarction after ozone therapy: is ozone therapy Dr. Jekyll or Mr. Hyde? Cardiology 2015;132:101-4.

24. Bocci V, Brito GS. Ozone therapy in critical patients. Rationale of the therapy and proposed guidelines. Riv Ital 0ssigenoOzonoterapia 2006;5:7-11.

25. Viebahn-Hänsler R, León Fernández OS, Fahmy Z. Ozone in medicine: the low-dose ozone concept-guidelines and treatment strategies. Ozone Sci Eng 2012;34:408-24.

26. Sharma VK, Tsivgoulis G, Lao AY, Alexandrov AV. Role of transcranial Doppler ultrasonography in evaluation of patients with cerebrovascular disease. Curr Neurol Neurosci Rep 2007;7:8-20.

27. Panerai RB. Complexity of the human cerebral circulation. Philos T Roy Soc A 2009;367:1319-36.

28. Loughlin PJ, Pitton JW, Atlas LE. Bilinear time-frequency representations: new insights and properties. IEEE Trans Signal Process 1993;41:750-67.

29. Cowling BJ, Freeman G, Wong JY, et al. Preliminary inferences on the age-specific seriousness of human disease caused by avian influenza A(H7N9) infections in China, March to April 2013. Euro Surveill 2013;18:20475.

30. Sliwka U, Harscher S, Diehl RR, et al. Spontaneous oscillations in cerebral blood flow velocity give evidence of different autonomic dysfunctions in various types of headache. Headache 2001;41:157-63.

31. Teich MC, Lowen SB, Jost BM, et al. Heart rate variability: measures and models. In: Akay M, ed. Nonlinear biomedical signal processing dynamic analysis and modelling. New York: Wiley-IEEE Press; 2001. pp. 159-86.

32. De Riva N, Budohoski KP, Smielewski P, et al. Transcranial doppler pulsatility index: what it is and what it isn't. Neurocrit Care 2012; 17:58-66. 